\title{
ENTREVISTA COM ANDRÉ CZARNOBAI
}

\author{
Gabriela Terezinha Paulo ${ }^{1}$ \\ Jaqueline Sinderski Bigaton ${ }^{1}$ \\ -Universidade Federal de Santa Catarina \\ Florianópolis, Santa Catarina, Brasil
}

André Felipe Pontes Czarnobai nasceu em Porto Alegre, Rio Grande do Sul, no dia 27 de maio de 1979, e vive em São Paulo desde 2012. Mais conhecido como Cardoso, Kidids ou Dids, formou-se em jornalismo pela Faculdade de Biblioteconomia e Comunicação Social, pela Universidade Federal do Rio Grande do Sul (Fabico/UFRGS), em 2003. Atua, principalmente, como escritor, tradutor, roteirista e consultor criativo para veículos de comunicação, mercado editorial, agências de publicidade e produtoras de audiovisual.

Como escritor, André Czarnobai publicou os livros Cavernas \& concubinas (2005), sob o pseudônimo Cardoso, e $O$ sensual adulto, ainda no prelo. Faz parte da antologia digital Enter (2009), que foi organizada por Heloísa Buarque de Hollanda, com patrocínio da Secretaria de Cultura do Estado do Rio de Janeiro e apoio do Programa Avançado de Cultura Contemporânea (PACC/URFJ) e do Conselho Nacional de Desenvolvimento Científico e Tecnológico (CNPq), na qual publicou, sob o pseudônimo Cardoso, os textos Dali, O oitavo dia: Pafúncio e Prosopopéia estival e o vídeo Rio Dejeuner. Participou também das publicações Desacordo ortográfico, uma antologia de textos organizada por Reginaldo $\mathrm{Pu}$ jol Filho, e Ficção de Polpa 3, ambas publicadas, em 2009, pela Não Editora; Mitos Virtuais (2012), publicada pela editora Mundo Mirim; Contos do Novo Milênio (2006), organizada por Charles 
Kiefer e publicada pelo Instituto Estadual do Livro (IEL) e co-editada pela Corag; Contos de bolso (2005), publicada pela Casa Verde; Troco (2005), pela Type; Oficina 32 (2004), organizada por Luis Antonio de Assis Brasil e publicada pela Oficina de Criação Literária da Pontifícia Universidade Católica do Rio Grande do Sul (PUC-RS).

Foi editor e colunista do fanzine por e-mail "CardosOnline", criado em parceria com Daniel Galera, entre 1998 e 2001, do qual fizeram parte, como colunistas fixos, Daniel Galera, Marcelo Träsel, Guilherme Pilla, Daniel Pellizzari, Hermano Freitas, Clarah Averbuck e Guilherme Caon. Colaborou com jornais como Zero Hora e Folha de São Paulo e revistas como Piauí, Void e Trip. E recebeu o segundo prêmio na categoria "Jornalismo Online", do $21^{\circ}$ Prêmio de Direitos Humanos de Jornalismo, concedido pela Ordem do Advogados do Brasil (OAB), em 2004.

André Czarnobai traduziu mais de 25 livros para editoras como Companhia das Letras, Conrad, Seguinte, Claro Enigma, Três Estrelas, Paralela e Intríseca. Entre as publicações, destacam-se Por que esta noite é diferente das outras? (2016), Você não deveria estar na escola? (2015), 13 incidentes suspeitos (2014), Quando você a viu pela última vez? (2013) e Quem poderia ser a uma hora dessas? (2012), escritos por Lemony Snicket e publicados pela editora Seguinte; Se... (2016), de David J. Smith, e O livro dos maiores exploradores de todos os tempos (2013), de Peter Chrisp, ambos publicados pela Companhia das Letrinhas; Cadê você Bernadette? (2013), de Maria Semple, e Histórias da Bíblia (2012), de Michael Coleman, publicados pela Companhia das Letras; Breve História de Sete Assassinatos (2017), de Marlon James, publicado pela editora Intrínseca; Ninguém vira adulto de verdade (2016), de Sarah Andersen, O Código dos Bucaneiros (2016), de Caroline Carlson, Star Wars: A missão do contrabandista (2015), de Greg Rucka, Dia de folga (2013), de John Boyne, O histórico infame de Frankie Landau-Banks (2013), E. Lockhart, É o primeiro dia de aula... Sempre! (2012), de R.L. Stine, e Tutancâmon e sua tumba cheia de tesouros (2012), de Michael 
Cox, todos publicados pela editora Seguinte; Maracanã (2014), de Franklin Morales, pela editora Breve Companhia; e Albert Einstein e As Fronteiras Da Física (2013), de Jeremy Bernstein e $O$ que é arte contemporânea? (2012), de Jacky \& Susy Klein, ambos pela editora Claro Enigma.

Cadernos de Tradução (CT): Você trabalha somente com tradução? Há quanto tempo? (Se houver outras coisas e puder contar... Ex.: como surgem os trabalhos, convites, encomendas, desejo, se você escreve também.)

André Czarnobai $(A C)$ : Não, eu trabalho com muitas coisas, a maioria delas relacionadas ao texto. Já trabalhei como jornalista, escrevo roteiros para TV e o cinema e presto serviços de consultoria criativa para diversos mercados, com mais foco na publicidade e na internet. Todavia, nos últimos cinco anos tenho me focado bem mais na tradução, porque é algo que me dá bastante prazer, e eu me sinto pago para aprender (não apenas sobre os temas que traduzo, mas também linguagem - no mínimo duas, o idioma original e o idioma para o qual traduzo o texto). Os trabalhos surgem de maneira muito simples: uma tradução puxa a outra. Seu nome começa a aparecer nos livros e, se o trabalho é bom, os convites começam a surgir. Especialmente no meu caso, posto que também sou escritor e conheço muita gente no mercado editorial.

CT: De quais idiomas você costuma traduzir?

$A C$ : Inglês para português, mais de $90 \%$ dos livros que traduzi. Mas traduzi também do espanhol e, recentemente, do patois jamaicano, um dialeto que se fala apenas na Jamaica.

CT: Quantas obras você já traduziu? (Se quiser citar...) 
$A C$ : Pouco mais de 20, estão todas listadas aqui: < http://www. qualquer.org/curriculo.html $>^{1}$.

CT: Qual a sua relação com a literatura infantil e juvenil?

$A C$ : De tradutor, basicamente. Traduzi uns 4 ou 5 livros adultos, os outros todos foram infantis ou infanto-juvenis. Gosto bastante porque me sinto participando, ainda que indiretamente, da formação de novos leitores, o que deveria ser muito mais valorizado (sobretudo no nosso país).

CT: Você já havia traduzido outros livros do David J. Smith? Você teve algum contato com o autor?

$A C$ : O livro do David J. Smith foi um dos mais simples de traduzir, posto que era basicamente um livro ilustrado informativo. Não tive nenhum contato com o autor.

CT: Como foi traduzi-lo? (problemas encontrados, estratégias usadas...)

$A C$ : Muito fácil. Como eu disse, é um livro informativo, de não-ficção, com um uso muito simples da linguagem (afinal, é para crianças). Não lembro com exatidão, mas acho que me tomou entre uma semana e 10 dias de trabalho.

CT: Há alguma especificidade na tradução de obras infantis e juvenis?

${ }^{1}$ Página pessoal de André Czanorbai. 
$A C$ : Muitas, e varia muito de livro pra livro, mas talvez as principais sejam o uso de jogos de palavras e trocadilhos e um senso de humor muito presente. Frequentemente ouço alguém falando que um livro infantil parece ter sido fácil de traduzir, e é justamente aí que eu sei que fiz um bom trabalho. Livros infanto-juvenis costumam ser bem complicados por conta dessas particularidades (todavia, uma observação: "Se..." é um livro infantil; entre os infanto-juvenis que traduzi, destaco a série "Só perguntas erradas", do Lemony Snicket. Foram cinco livros, bastante complexos por conta de muitas relações internas entre os vários volumes, rimas, ditados, nomes de alimentos, plantas e animais que não existem no hemisfério sul).

CT: Como você se coloca na escolha entre domesticação e estrangeirização do texto fonte?

$A C$ : Depende do público alvo. Para crianças, opto sempre pela domesticação. Procuro produzir o texto mais legível possível. Para adolescentes, opto por um texto intermediário, que contenha alguns elementos domesticados, mas também respeite trocadilhos e referências originais. Nos adultos é parecido, mas aí a balança tende a pender mais para respeitar as intenções originais do autor.

CT: Como você vê o mercado de tradução infantil e juvenil no Brasil?

$A C$ : Excelente, posto que é um setor muito valorizado, com tiragens geralmente mais altas que as dos livros de ficção adulta (e vendas que acompanham essa lógica, em média).

CT: Você pode falar um pouco sobre o processo de tradução da obra do Lemony Snicket? Você sentiu alguma diferença à medida 
em que foi traduzindo os livros dele? Foi ficando mais fácil por ir aumentando o domínio sobre a linguagem do autor ou não?

$A C$ : Foi um processo divertido, mas bem cansativo, posto que os primeiros 3 volumes foram lançados ao mesmo tempo aqui e nos Estados Unidos. Eu recebia os manuscritos e traduzia em sigilo em prazos curtíssimos para dar tempo. Nem sei que processos corriam ao mesmo tempo na editora, mas imagino que tenha sido tudo muito insano. No mais, sim, acontece exatamente o que tu disse: vai ficando mais fácil porque tu começa a entender a cabeça do autor, e lá pelas tantas emula a voz dele com muita facilidade (pelo menos no meu caso). Mas aí também gera um problema, porque tu fica rigoroso com o texto, quer usar as mesmas palavras, as mesmas expressões, e isso te faz ficar voltando aos outros livros de forma quase maníaca pra que tudo fique perfeito (e pior: quase ninguém ou ninguém percebe).

CT: Você mencionou que as traduções vão aparecendo à medida em que seu trabalho vai ficando mais conhecido. Nesse sentido, como você vê o debate sobre invisibilidade do trabalho do tradutor?

$A C$ : Não me incomoda em nada. Não vejo como "meu" trabalho. Sim, é claro que traduzir é reescrever, é reinventar. Toda tradução é uma versão e, nessa medida, estou realizando um trabalho criativo também - em alguns casos, estou "escrevendo" um livro do zero. Mas nunca é totalmente do zero. Ele é do zero do ponto de vista da linguagem, não das situações, das técnicas, da estrutura. Isso é muito mais difícil, e quem merece louros por esses feitos é o autor, independente da língua em que tenha produzido. Talvez eu pense dessa forma porque também escrevo, e produzo a minha obra paralelamente a isso. 
CT: Qual a diferença entre ser um tradutor que escreve e um escritor que traduz? Como isso se reflete no texto escrito e nas traduções?

$A C$ : Do meu ponto de vista, nenhuma. É só um jogo de palavras. Dá até pra evocar a matemática aqui: a ordem dos fatores não altera o produto. Talvez a pergunta faça mais sentido se há um senso de vocação aqui, do tipo: alguém que apenas traduzia, começa a se inspirar com as obras que traduz e resolve virar um escritor. Não é meu caso e não conheço ninguém que se enquadre nessa descrição. Daniel Galera, Antônio Xerxenesky, Daniel Pellizzari, Joca Reiners Terron: todos meus amigos, todos são escritores e tradutores. Escrevem porque gostam e traduzem porque é uma forma de se ganhar dinheiro estando muito perto daquilo que gostam de fazer. Acho que, na média, é isso que acontece. Sei do exemplo do Caetano Galindo, por exemplo, que foi na direção contrária: traduziu vários tomos volumosos e complexos, depois resolveu escrever seu próprio livro. Como não sou próximo dele, não sei se o processo é diferente no caso dele. Talvez seja, talvez não.

\section{Referências}

ANDERSEN, Sarah. Ninguém vira adulto de verdade. Tradução de André Czarnobai. São Paulo: Seguinte, 2016.

BERNSTEIN, Jeremy. Albert Einstein e as fronteiras da fisica. Tradução de André Czarnobai. São Paulo: Claro Enigma, 2013.

BOYNE, John. Dia de folga. Tradução de André Czarnobai. São Paulo: Seguinte, 2013. 
BRASIL, Luis Antonio de Assis (Org.). Oficina 32 - Oficina de Criação Literária. Porto Alegre: PUC-RS, 2004.

CARDOSO [André Czarnobai]. Cavernas \& concubinas. São Paulo: DBA, 2005

CARLSON, Caroline. O código dos bucaneiros. Tradução de André Czarnobai. São Paulo: Seguinte, 2016.

CHAFFE, Laís (Org.). Contos de bolso. Porto Alegre: Casa Verde, 2005.

CHRISP, Peter. O livro dos maiores exploradores de todos os tempos. Tradução de André Czarnobai. São Paulo: Companhia das Letrinhas, 2013.

COLEMAN, Michael. Histórias da Bíblia. Tradução de André Czarnobai. São Paulo: Companhia das Letras, 2012.

COX, Michael. Tutancâmon e sua tumba cheia de tesouros. Tradução de André Czarnobai. São Paulo: Seguinte, 2012.

CZARNOBAI, André. Currículo. Disponível em: : < http://www.qualquer.org/ curriculo.html >. Acesso em: 12 jun. 2017.

CZARNOBAI, André et al. Dentro de um livro. Rio de Janeiro: Casa da Palavra, 2005.

CZARNOBAI, André et al. Troco. Porto Alegre: Type, 2005.

HOLLANDA, Heloísa Buarque de (Org.) Enter - Antologia digital. Rio de Janeiro: O Instituto; Secretaria do Estado de Cultura do Rio de Janeiro, 2009. Disponível em: < http://www.oinstituto.org.br/enter/ > . Acesso em: 12 jun. 2017.

JAMES, Marlon. Breve História de Sete Assassinatos. Tradução de André Czarnobai. Rio de Janeiro: Intrínseca, 2017.

KIEFER, Charles (Org.). Contos do novo milênio - Os melhores contistas gaúchos dos últimos 25 anos. Porto Alegre: IEL; Corag, 2006. 
KLEIN, Jacky; KLEIN, Suzy. O que é arte contemporânea? Tradução de André Czarnobai. São Paulo: Claro Enigma, 2012.

LOCKHART, E. O histórico infame de Frankie Landau-Banks. Tradução de André Czarnobai. São Paulo: Seguinte, 2013.

MACHADO, Samir Machado de (Org.). Ficção de Polpa. v. 3. Porto Alegre: Não Editora, 2009.

MAIA, Ana Paula; CARDOSO [André Czrnobai]; LOPES, Francis; STANISIERE, Inês; SPALDING, Marcelo. Mitos virtuais. São Paulo: Mundo Mirim, 2012.

MORALES, Franklin. Maracanã. Tradução de André Czarnobai. São Paulo: Breve Companhia, 2014.

PUJOL FILHO, Reginaldo (Org.). Desacordo ortográfico. Porto Alegre: Não Editora, 2009.

RUCKA, Greg. Star Wars: a missão do contrabandista. Tradução de André Czarnobai. São Paulo: Seguinte, 2015.

SEMPLE, Maria. Cadê você Bernadette? Tradução de André Czarnobai. São Paulo: Companhia das Letras, 2013.

SMITH, David J. Se... Tradução de André Czarnobai. São Paulo: Companhia das Letrinhas, 2016.

SNICKET, Lemony. 13 incidentes suspeitos. Tradução de André Czarnobai. São Paulo: Seguinte, 2014. . Por que esta noite é diferente das outras? Tradução de André Czarnobai. São Paulo: Seguinte, 2016. . Quando você a viu pela última vez? Tradução de André Czarnobai. São Paulo: Seguinte, 2013. 
. Quem poderia ser a uma hora dessas? Tradução de André Czarnobai. São Paulo: Seguinte, 2012.

. Você não deveria estar na escola? Tradução de André Czarnobai. São Paulo: Seguinte, 2015.

STINE, Robert Lawrence. É o primeiro dia de aula... Sempre! Tradução de André Czarnobai. São Paulo: Seguinte, 2012.

Recebido em: 13/04/2018

Aceito em: 13/07/2018 Publicado em setembro de 2018

Gabriela Terezinha Paulo. E-mail: gabidipaulo@gmail.com ORCID: https://orcid.org/0000-0001-5850-2618 Jaqueline Sinderski Bigaton. E-mail: jaquelinesinderski@gmail.com ORCID: https://orcid.org/0000-0003-2168-4846 